\title{
Orciprenaline in Treatment of Airways Obstruction in Chronic Bronchitis
}

\author{
GORDON EDWARDS,* M.B.E., M.B., M.R.C.P.
}

Brit. med. F., 1964, 1, 1015-1017

Adrenaline and structurally similar catechol amines have been used in the treatment of bronchial asthma for many years. The clinical use of isoprenaline in this condition was first described by Stolzenberger-Seidel (1940), since when it has been used extensively. Although taken sublingually isoprenaline is an effective bronchodilator; it is not active when swallowed. Since it is rapidly metabolized its duration of action is short, and unpleasant side-effects may occur. For these reasons a bronchodilator without these disadvantages, but with comparable clinical effectiveness, was sought, and orciprenaline, a chemically similar compound, was found to fulfil these criteria in laboratory animals (Engelhardt et al., 1961).

Orciprenaline ("alupent") is a racemic isomeric mixture differing only from isoprenaline in having both the hydroxyl groups of its benzene ring in the meta position, while isoprenaline has one of these groups in the para position.

Spitzbarth and Albers (1961) claimed that tachycardia and myocardial irritability with resultant arrhythmias were much less easily produced with orciprenaline than with isoprenaline. They also reported that orciprenaline had a longer duration of action and caused less intestinal upset. Beynon-Jones (1962) and Drewitt (1962) claimed satisfactory clinical response to orciprenaline $40-80 \mathrm{mg}$. daily in patients with asthma or chronic bronchitis. Myers and Coltman (1963), in a double-blind controlled trial in general practice, found that orciprenaline $60 \mathrm{mg}$. daily compared favourably with ephedrine hydrochloride $180 \mathrm{mg}$. daily in patients with asthma or chronic bronchitis.

\section{Plan of Trial}

The investigations were designed to assess the toxicity of orciprenaline, to determine its value in controlling reversible bronchospasm or airways obstruction, and to assess its clinical effectiveness in relieving wheezing in the chronic bronchitic in remission.

Chronic bronchitis was defined as that condition characterized by cough with sputum which occurred on most days for at least three months in the year for two years or more, and associated with some degree of exertional dyspnoea and wheezing, for which no other clinical condition was respon-

- Phyaldan, General Infirmary at Leeds; Senior Chest Physician, Deparuinent of Respiratory Diseases, Killingbeck Hospital, Leeds. sible. The forced expiratory volume in one second (F.E.V.. was required to be improved by at least $10 \%$ following three minutes' rest after 60 seconds' inhalation of a standard bronchodilator ( $1 \%$ isoprenaline aerosol) delivered by a Collison inhaler, on at least two occasions in the week before entry to the trial. To reduce the effects of the known daily fluctuations in ventilatory function (Lewinsohn et al., 1960), all ventilatory estimations were performed between 11 a.m. and 3 p.m., and the mean of three consecutive readings was recorded.

\section{Methods}

\section{Toxicity Studies}

Initially, $60,80,100$, or $120 \mathrm{mg}$. of orciprenaline in three divided doses daily for seven days were allotted at random to four groups, each consisting of eight hospital in-patients. Later another 43 hospital patients were also randomly allocated to a seven-day course of treatment with 60,80 , or $100 \mathrm{mg}$. of orciprenaline daily. All 75 patients were examined daily to estimate the pulse rate and rhythm, the blood-pressure, the presence of glycosuria or urinary retention and of palpitations, flushings, or gastro-intestinal disturbances.

Side-effects were classed as being "severe" when their presence necessitated withdrawal of treatment, "moderate" if the patient complained of them spontaneously, "mild" if they were revealed only after direct questioning, and as "transient" when they lasted for a few hours only, or "continuous" if they persisted as long as the drug was maintained in that dosage.

\section{Results}

The results of the toxicity studies in all 75 patients are shown in Table I. Doses up to $100 \mathrm{mg}$. daily were well tolerated and toxic effects were not usually severe. Above this level, however, toxic reactions were frequent, continuous, and severe. The most common complaint was of trembling. Palpitation was the next most frequently observed side-effect, while gastro-intestinal and urinary symptoms were uncommon with daily doses of less than $100 \mathrm{mg}$. Of eight patients taking $120 \mathrm{mg}$. daily, six complained of continuous moderate or severe toxic symptoms and four had to withdraw from the trial. In two of the three patients whose systolic blood-

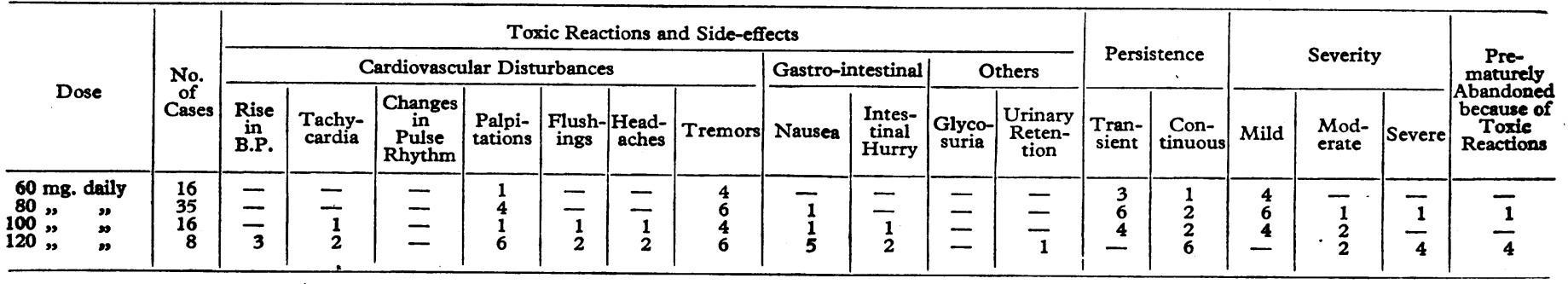


pressure increased while taking $120 \mathrm{mg}$. daily the rise occurred only once. In the third patient the rise of $30 \mathrm{~mm}$. in the systolic pressure persisted for 48 hours only and then settled spontaneously while treatment continued. All side-effects from whatever dosage disappeared when the drug was discontinued.

\section{Control of Airways Obstruction : Acute Studies}

\section{Methods}

The degree and duration of the bronchodilator effect of orciprenaline by inhalation was compared double-blind with $1 \%$ isoprenaline in hospital patients, estimating the F.E.V. before and after 60 seconds' inhalation of an aerosol of the test solutions. All other treatments were withdrawn on admission to hospital. Ventilatory function tests were carried out on the day of admission and on the third and fifth days at 11 a.m., 1 p.m., and 3 p.m. The test inhalations were given in random order on alternate days. Subsequent spirometric studies were repeated at the same time on the appropriate days.

The effects of $2 \%$ and $5 \%$ orciprenaline and of a single dose of $20 \mathrm{mg}$. of orciprenaline by mouth were compared with the results after $1 \%$ isoprenaline aerosol, a blank placebo aerosol, and an indistinguishable placebo tablet. The F.E.V.1 was estimated before exposure, and at $3,15,30,60,120,180$, and 240 minutes afterwards, in 14 chronic wheezy bronchitic patients who were admitted to hospital for this purpose and seven of whom had taken part in a pilot study.

\section{Resuits}

Changes from the mean resting F.E.V..$_{1}$ in the 14 patients at specified times after exposure to the agents under test are

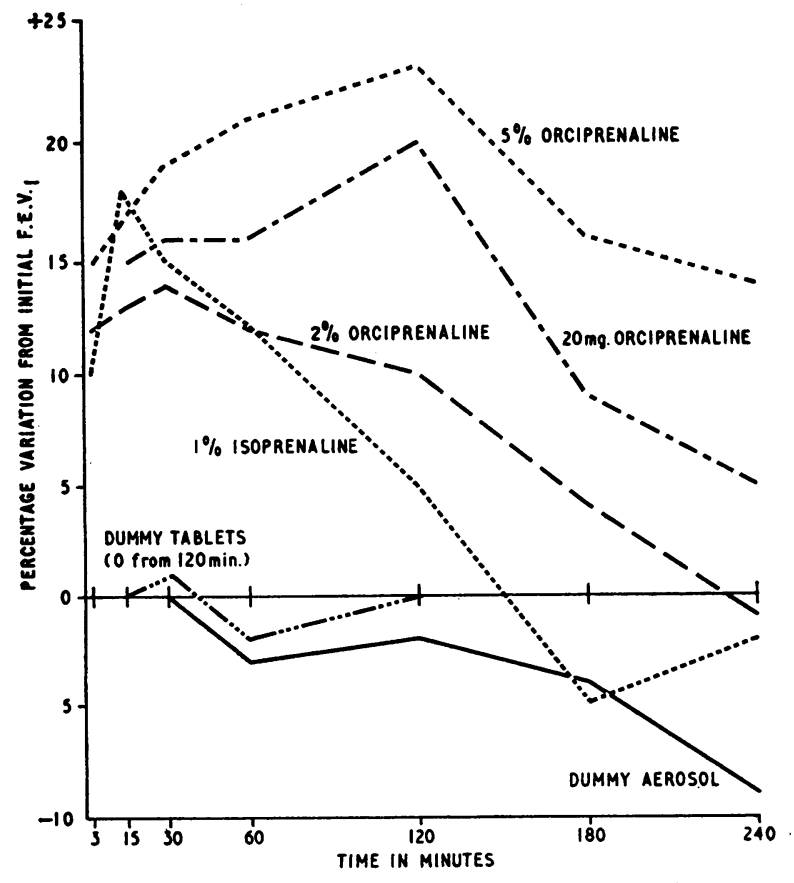

Percentage variation of mean F.E.V., according to time and treatment.

shown graphically in the Chart, where they are expressed as percentage variations of the resting F.E.V.1. The average resting pre-inhalation F.E.V..$_{1}$ was about 0.851 . for all the drug tests and about 11 . for the placebos. There were appreciable differences in the time of appearance and the size and duration of the bronchodilator effect after the various preparations; but there was little difference between the effects following $2 \%$ orciprenaline and $1 \%$ isoprenaline. In both the action was immediate, and the maximal effect occurred within 30 minutes and persisted for about another two hours. The effect of $2 \%$ orciprenaline, however, was apparently more sustained.

Inhalation of $5 \%$ orciprenaline also produced an immediate response, which was greater than that after $1 \%$ isoprenaline. This response reached a maximum at two hours and persisted for another two hours. The improvement at four hours after $5 \%$ orciprenaline was about the same as the improvement seen at 30 minutes after $1 \%$ isoprenaline.

One single oral dose of $20 \mathrm{mg}$. of orciprenaline produced a response similar to that after a $5 \%$ aerosol; the maximal improvement also occurred at two hours and was still measurable after four hours. Neither of the placebo materials produced any improvement in the resting F.E.V.1

\section{Clinical Response : Seven-day Studies}

\section{Methods}

The value of seven days' oral orciprenaline therapy in relieving airways obstruction in the chronic bronchitic was assessed by a double-blind controlled crossover trial in 37 out-patients. The effects of $20 \mathrm{mg}$. of orciprenaline when taken three times daily were compared with the effects of an indistinguishable placebo, when each was given for seven days to each patient in succession. The order in which the tablets were taken was decided from a previously prepared randomized table. Each patient was investigated on admission to the trial and again after one week off all therapy. One course of treatment was then given and the tests were repeated after seven days. Then the second preparation was issued for another seven days' treatment, after which the investigations were again repeated.

On admission to the trial the participants were instructed that they would be required to say which of the two treatments they preferred. A closed sequential scheme for withinsubject comparisons (Armitage, 1960) was used so that a significant result (at $5 \%$ ) should be obtained if $80 \%$ of the preferences in the population were for one treatment. At the end of each patient's trial, in answer to the question "Which tablet was most effective in relieving your wheezing?", a simple preference was expressed for one or other tablet, or for neither treatment.

\section{Results}

Two patients failed to complete the trial, one because she relapsed so severely on the placebo tablets that she required hospital admission and additional treatment, and the other because she failed to keep her clinic appointments.

After the expression of 24 preferences-18 for orciprenaline, 4 for the placebo, and 2 for neither treatment-the upper outer boundary of the sequential diagram was crossed, suggesting that orciprenaline gave better subjective relief than the placebo, significant at the $5 \%$ level. The trial was continued until all 35 patients had completed their treatments; 24 of them preferred orciprenaline, 6 preferred the placebo, and 5 expressed no preference.

A close association was apparent between the objective changes in ventilatory function after orciprenaline therapy and the patients' subjective preferences. Of the 24 patients who expressed a preference for orciprenaline, 23 showed improvement in the F.E.V..$_{1}$ and the order of treatment did not influence the results. 
A mean improvement of $21.5 \%$ of the F.E.V. ${ }_{1}$ was observed in 32 of the 35 patients after seven days' orciprenaline therapy compared with the before-treatment control value $(t=6.68$; $P<0.001$ ). No such improvement followed 7 days' placebo treatment ; indeed, the majority of the patients -25 out of 35 -deteriorated, the mean F.E.V. ${ }_{1}$ showing a significant decrease of $-8.8 \%(t=2.89 ; \mathrm{P}<0.01)$. Twenty-eight patients demonstrated a reduction in the degree of residual reversible airways obstruction after orciprenaline therapy, by an average of $-7.4 \%(t=2.67 ; P<0.05)$. On the contrary, the average degree of residual reversible airways obstruction after the placebo was increased by $5.4 \%$, which, however, was not statistically significant $(t=1.65 ; \mathrm{P}>0.05)$.

Eighteen patients received the placebo first, of whom 2 were lost from the trial, and 19 started with orciprenaline. The mean F.E.V. ${ }_{1}$ at the three stages of the trial-namely, before treatment, after seven days' placebo, and after 7 days' orciprenaline-in these two groups is shown in Table II. After $60 \mathrm{mg}$. of orciprenaline daily for seven days the mean F.E.V. ${ }_{1}$ is significantly increased compared with after the placebo $(P<0.01)$, and this was the case whichever tablet was given first.

\begin{tabular}{|c|c|c|c|c|c|c|}
\hline \multirow{3}{*}{$\begin{array}{c}\text { Order } \\
\text { of } \\
\text { Starting } \\
\text { Treatment }\end{array}$} & \multirow{3}{*}{$\begin{array}{l}\text { No. of } \\
\text { Cases }\end{array}$} & \multicolumn{3}{|c|}{ Mean F.E.V.1 } & \multirow{3}{*}{$\begin{array}{l}\text { Difference } \\
\mathrm{O}-\mathrm{P}^{*}\end{array}$} & \multirow{3}{*}{$\begin{array}{c}\text { Difference } \\
\mathrm{O}-\mathrm{B}^{*}\end{array}$} \\
\hline & & \multirow{2}{*}{$\begin{array}{l}\text { Control } \\
\text { before } \\
\text { Treatment } \\
\text { (B) }\end{array}$} & \multicolumn{2}{|c|}{$\begin{array}{c}\text { After } 7 \text { Days' } \\
\text { Treatment }\end{array}$} & & \\
\hline & & & $\begin{array}{l}\text { With } \\
\text { Placebo } \\
\text { (P) }\end{array}$ & $\begin{array}{l}\text { With Orci- } \\
\text { prenaline } \\
\text { (O) }\end{array}$ & & \\
\hline \multirow{2}{*}{$\begin{array}{l}\text { Placebo first } \\
\text { Drcipren- } \\
\text { aline first }\end{array}$} & 16 & $1 \cdot 12$ & 1.06 & 1.31 & $0.25 \pm 0.052$ & $0.19 \pm 0.044$ \\
\hline & 19 & $1 \cdot 23$ & $1 \cdot 12$ & $1 \cdot 38$ & $0.26 \pm 0.073$ & $0.14 \pm 0.059$ \\
\hline
\end{tabular}

* Mean difference and standard error are calculated from individual differences from each patient.

The differences in the mean percentage improvement of F.E.V. ${ }_{1}$ to a $1 \%$ isoprenaline aerosol following the two courses of treatment in the two groups are shown in Table III. Orciprenaline produced a significant reduction in the degree of residual reversible bronchospasm $(P<0.05)$, but after one week's treatment with placebo no significant change occurred, although a slight increase in the degree of bronchospasm was observed ( $\mathrm{P}>0.05)$.

TABLE III.-Altered Response to Isoprenaline Inhalation After Seven Days' Therapy Related to Treatment Sequence

\begin{tabular}{|c|c|c|c|c|c|c|}
\hline \multirow{3}{*}{$\begin{array}{c}\text { Order of } \\
\text { Starting } \\
\text { Treatment }\end{array}$} & \multirow{3}{*}{$\begin{array}{c}\text { No. } \\
\text { of } \\
\text { Patients }\end{array}$} & \multicolumn{3}{|c|}{$\begin{array}{l}\text { Mean Percentage Improve- } \\
\text { ment of F.E.V.1 to } 1 \% \\
\text { Isoprenaline Aerosol }\end{array}$} & \multirow{3}{*}{$\begin{array}{c}\text { Difference } \\
\mathrm{O}-\mathrm{P}^{*}\end{array}$} & \multirow{3}{*}{$\begin{array}{c}\text { Difference } \\
{\mathrm{O}-\mathrm{B}^{*}}^{*}\end{array}$} \\
\hline & & \multirow{2}{*}{$\begin{array}{l}\text { Control } \\
\text { before } \\
\text { Treat- } \\
\text { ment } \\
\text { (B) }\end{array}$} & \multicolumn{2}{|c|}{$\begin{array}{c}\text { After } 7 \text { Days' } \\
\text { Treatment }\end{array}$} & & \\
\hline & & & $\begin{array}{l}\text { With } \\
\text { Placebo } \\
\text { (P) }\end{array}$ & $\begin{array}{c}\text { With } \\
\text { Orci- } \\
\text { prenaline } \\
(\mathrm{O})\end{array}$ & & \\
\hline \multirow{2}{*}{$\begin{array}{l}\text { Placebo } \\
\text { first ... } \\
\text { Orcipren- } \\
\text { aline first }\end{array}$} & 16 & $18 \cdot 1$ & 23.9 & $4 \cdot 2$ & $-19 \cdot 73 \pm 5 \cdot 97$ & $-13.92 \pm 3.66$ \\
\hline & 19 & $17 \cdot 4$ & $27 \cdot 4$ & $16 \cdot 0$ & $-11 \cdot 4 \pm 3 \cdot 40$ & $-1.40 \pm 3.48$ \\
\hline
\end{tabular}

* Mean difference and standard error are calculated from individual differences for each patient.

Toxic effects from the drugs in this part of the trial presented no difficulties. Mild reactions from orciprenaline occurred in 11 patients, while moderate effects were complained of by three others ; on the placebo tablets five patients had mild reactions and two had moderate toxic effects. The incidence of toxic reactions was not significantly different in these two groups $\left(\chi^{2}=3.3 ; \mathrm{P}>0.10\right)$.

\section{Conclusions}

The relief of airways obstruction and wheezing in chronic bronchitis is of considerable practical importance : isopren- aline, which can usefully be given only sublingually or by aerosol, is often used for this purpose. In addition to the limited routes of therapy, it is a relatively toxic substance, with only a short period of effective activity. A bronchodilator which is effective by mouth, non-toxic, and has a rapid and prolonged action would be valuable in the management of patients with bronchospasm. Orciprenaline fulfils these requirements. It has here been shown to be without significant side-effects except in large doses, and effective in controlling airways obstruction in the chronic bronchitic patient, whether given by mouth or aerosol.

A $2 \%$ aerosol solution of orciprenaline had an action similar in quality and duration to $1 \%$ isoprenaline. A $5 \%$ orciprenaline aerosol was more effective in relieving bronchospasm. After 30 minutes it produced a greater reversal of airways

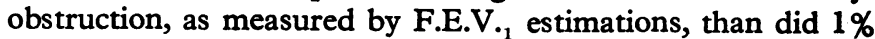
isoprenaline, and its effect persisted for four hours at least. Similar results followed the use of a single dose of $20 \mathrm{mg}$. of orciprenaline by mouth. The duration of action of $5 \%$ orciprenaline is about eight times longer than that usually obtained after $1 \%$ isoprenaline, and its peak action is $33 \%$ higher.

Although a total daily dose of $100 \mathrm{mg}$. of orciprenaline can be given before severe and continuous side-effects make their appearance, an effective clinical response without significant toxicity can be achieved by $20 \mathrm{mg}$. three times daily. The incidence of side-effects after orciprenaline $60 \mathrm{mg}$. daily was not significantly different from that following an indistinguishable placebo.

\section{Summary}

Orciprenaline ("alupent"), an analogue of isoprenaline, was significantly effective in the relief of airways obstruction in patients with chronic bronchitis, whether taken by mouth or by inhalation, as shown in a seven-day controlled doubleblind trial.

Toxic effects were not troublesome after inhalations or when doses of up to $100 \mathrm{mg}$. daily were swallowed.

A close association between subjective response as expressed in a double-blind sequential preferential trial in 35 patients and objective variation in serial ventilatory studies was demonstrated.

Orciprenaline was relatively non-toxic with a rapid and prolonged bronchodilator effect, and effective clinical response followed $60 \mathrm{mg}$. daily.

I am indebted to Dr. Karen Madsen for her assistance in carrying out these investigations while the patients were in hospital. I am grateful to Dr. Ruth Porter, of the medical department of Boehringer Ingelheim Ltd., who made available the tablets and aerosols of alupent, together with the appropriate placebos, and for her valuable suggestions and criticisms; and particularly am I indebted to Mr. Michael Curwen, of the Department of Medical Statistics, St. Bartholomew's Hospital, for his statistical advice on the arrangement of the trial and the interpretation of the results.

\section{REFERENCES}

Armitage, P. (1960). Sequential Medical Trials, p. 30. Blackwell, Oxford Beynon-Jones, D. C. (1962). Brit. F. clin. Pract., 16, 803.

Drewitt, A. H. (1962). Ibid., 16, 549.

Engelhardt, A., Hoefke, W., and Wick, H. (1961). Arzneimittel-Forsch. 11, 521.

Lewinsohn, H. C., Capel, L. H., and Smart, J. (1960). Brit. med. F., 1 , 462.

Myers, W. H., and Coltman, R. S. (1963). Med. Dig. (Lond.), 8, 95

Spitzbarth, H., and Albers, P. (1961). Arzmeimittel-Forsch., 11, 528. Stolzenberger-Seidel, M. (1940). Klin. W schr., 19, 1306. 